\title{
Commentary: A symmetrical bicuspid aortic valve is not just $180^{\circ}$
}

\author{
Stefano Mastrobuoni, MD, MPH, Laurent de Kerchove, MD, PhD, and Gebrine El Khoury, MD
}

\footnotetext{
From the Cardiovascular and Thoracic Surgery Department, Saint-Luc's Hospital Catholic University of Louvain, Brussels, Belgium.

Disclosures: Authors have nothing to disclose with regard to commercial support.

Received for publication June 4, 2019; accepted for publication June 5, 2019; available ahead of print July 16 , 2019.

Address for reprints: Stefano Mastrobuoni, MD, MPH, Cardiovascular and Thoracic Surgery Department, SaintLuc's Hospital, Ave Hippocrate 10, 1200 Brussels, Belgium (E-mail: Stefano.mastrobuoni@uclouvain.be). J Thorac Cardiovasc Surg 2020;159:e39-40 $0022-5223 / \$ 36.00$

Copyright (C) 2019 by The American Association for Thoracic Surgery https://doi.org/10.1016/j.jtcvs.2019.06.014
}

Type 0 bicuspid aortic valves (BAVs) according to Sievers classification $^{1}$ present 2 symmetrical cusps of same size with a perfectly fused cusp, no raphe, and symmetrical anterior and posterior annulus. These valves have shown improved results after repair compared with type $1,{ }^{2}$ where there is an incomplete fusion of the conjoined cusps with a raphe and a certain degree of asymmetry between the fused and nonfused cusps. In recent years, we have observed an increased interest in achieving the symmetry during type 1 BAV repair to approach the type 0 configuration and improved results. With this scope in mind, Urbanski $^{3}$ presents a technique that restore the $180^{\circ}$ commissural orientation with, on the one hand, a vertical plication of the sinus corresponding to the fused cusp, which is the larger the more pronounced the asymmetry, and on the other hand, a patch enlargement of the sinus corresponding to the nonfused cusp. In this way, by pulling the commissures toward the line of fusion and by enlarging the opposite sinus, the author achieves a symmetrical commissure orientation. Replacement of the ascending aorta, as in the case presented, further allows stabilization of the sinotubular junction (STJ). However, the ventricular-aortic junction (VAJ) is not addressed with the proposed technique. We agree that the $180^{\circ}$ configuration should be within the aims of BAV repair; however, we believe that the symmetry should be at all 3 levels of the valve: the VAJ, Valsalva sinuses, and the STJ. The reorientation of just the commissures to $180^{\circ}$ does not mean a real symmetrical valve and may not be enough to ensure valve durability over time. The sinus plication may improve the mobility of the fused cusp, but the sinus enlargement on the opposite side by increasing the intercommissural space may indeed reduce the mobility of the nonfused cusp. The valvesparing root replacement with the reimplantation technique addresses the issue of BAV symmetry at all levels. The proximal suture line with 10 to 12 pledged stitches allows first a complete circumferential stabilization of the VAJ and, particularly in type $1 \mathrm{BAV}$, a selective annular

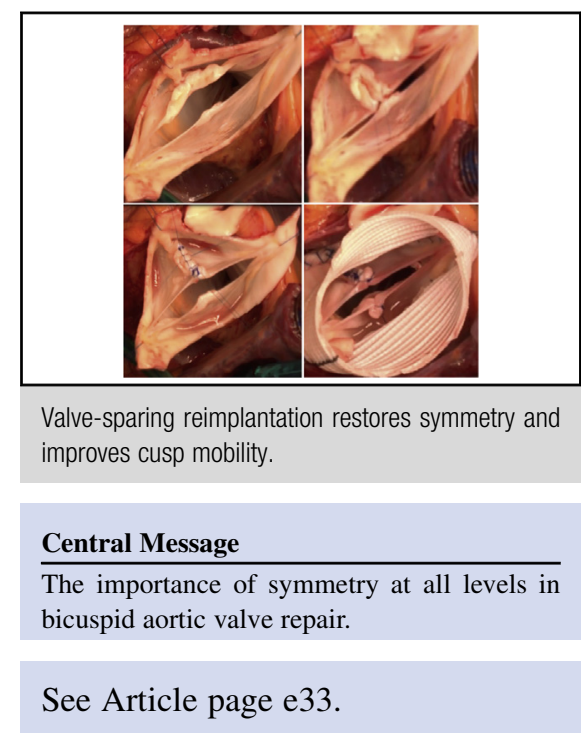

reduction at the level of the fused cusp. Commissure reimplantation at $180^{\circ}$ into the vascular graft is then straightforward. Several studies have shown that circumferential annuloplasty of the VAJ is associated with improved repair durability. $^{4-6}$ For years we have employed the reimplantation technique in BAV repair for severe aortic insufficiency even in not-dilated roots precisely to restore the symmetry and stabilize the aortic valve function. ${ }^{7}$ Type $1 \mathrm{BAV}$ can present in reality with a large spectrum of configurations depending on commissural orientation, length of fusion, height of the nonfunctional commissure. We have tried to systematize the most common configurations in a repair-oriented classification. ${ }^{8}$ The case presented by Urbanski, ${ }^{3}$ who is to be congratulated for the surgical results, is nonetheless not among the most difficult cases for repair. It seems that the main indication in this patient was ascending aorta dilatation associated with normal root and moderate aortic regurgitation. We agree that a technique simpler than the reimplantation-particularly in elderly patients - may do the job. But in younger patients, and in cases of severe aortic insufficiency and VAJ dilatation, we believe that a comprehensive approach to BAV disease is necessary. An important drawback of the proposed technique is the need for a pericardial patch to repair the fused cusp even after commissure reorientation. The reimplantation technique, with the selective anterior annular reduction, allows instead correction of cusp restriction (Figure 1) without the use of pericardial patch that is associated with late failures in all series. ${ }^{9,10}$ 

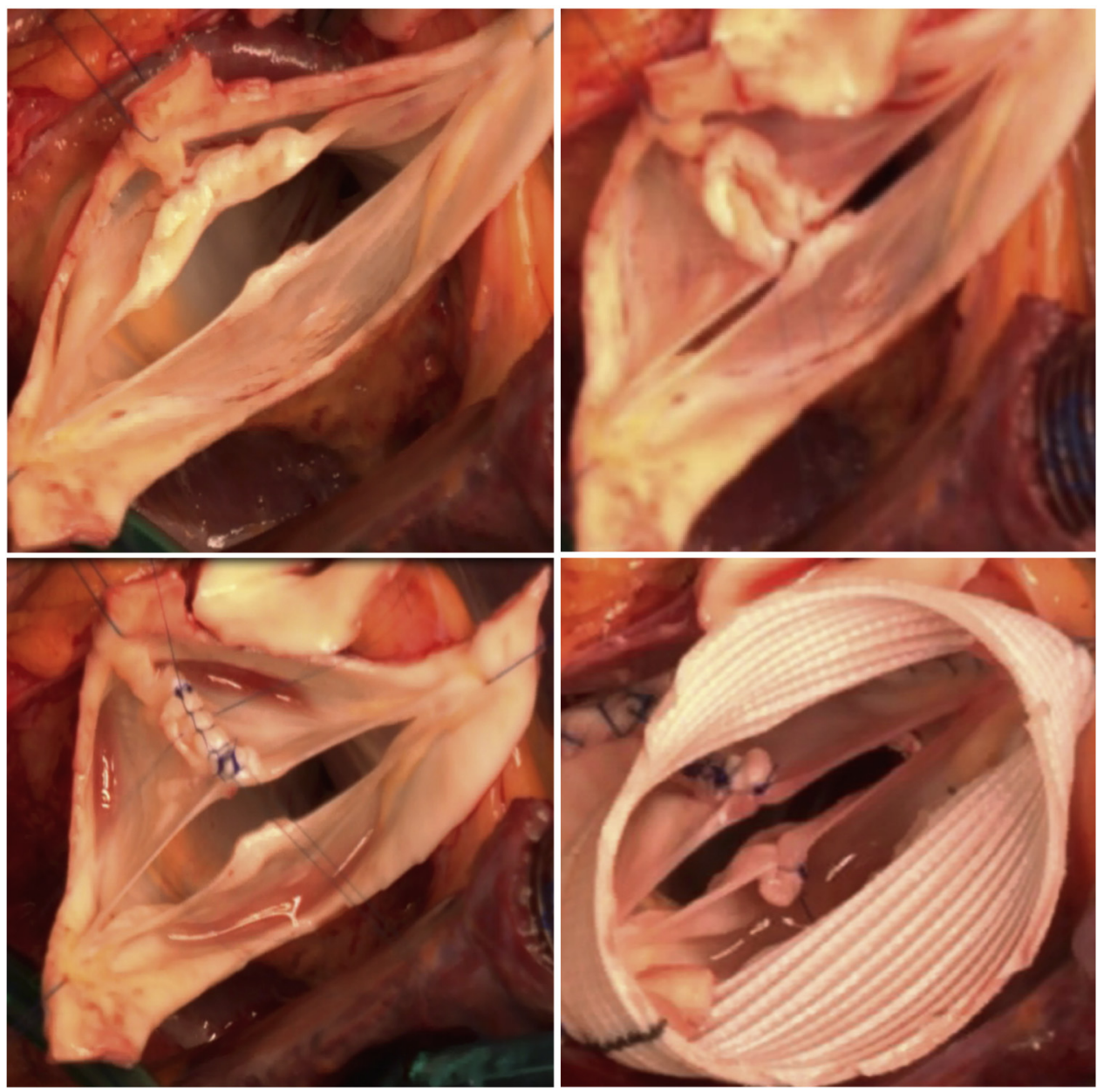

FIGURE 1. Valve-sparing reimplantation restores symmetry and improves cusp mobility.

The technique proposed by Urbanski is a simple and elegant approach to BAV repair that may work well in some selected cases but in most cases of severe BAV regurgitation the conventional valve-sparing root replacement techniques should be considered.

\section{References}

1. Sievers HH, Schmidtke C. A classification system for he bicuspid aortic valve from 304 surgical specimens. J Thorac Cardiovasc Surg. 2007;133:1226-33.

2. Kari FA, Kvitting JP, Stephens EH, Liang DH, Merk DR, Fischbein MP, et al. Tirone David procedure for bicuspid aortic valve disease: impact of root geometry and valve type on mid-term outcomes. Interact Cardiovasc Thorac Surg. 2014; 19:375-81.

3. Urbanski PP. Repair of bicuspid aortic valve: simple and effective achievement of symmetric valve orientation. J Thorac Cardiovasc Surg. 2020;159:e33-6.

4. Schneider U, Hoffman C, Aicher D, Takahashi H, Mioura Y, Schaëfers HJ. Suture annuloplasty significantly improves the durability of bicuspid aortic valve repair. Ann Thorac Surg. 2017;103:504-10.
5. de Kerchove L, Boodhwani M, Glineur D, Vandyck M, Vanoverschelde JL, Noirhomme P, et al. Valve sparing-root replacement with the reimplantation technique to increase the durability of bicuspid aortic valve repair. J Thorac Cardiovasc Surg. 2011;142:1430-8.

6. Lansac E, Di Centa I, Sleilaty G, Lejeune S, Berrebi A, Zacek P, et al. Remodeling root repair with an external aortic ring annuloplasty. J Thorac Cardiovasc Surg. 2017; 153:1033-42.

7. Mastrobuoni S, de Kerchove L, Navarra E, Watremez C, Vancraeynest D, Rubay J, et al. Long-term experience with valve-sparing reimplantation technique for the treatment of aortic aneurysm and aortic regurgitation. J Thorac Cardiovasc Surg. November 26, 2018 [Epub ahead of print].

8. de Kerchove L, Mastrobuoni S, Froede L, Tamer S, Boodhwani M, van Dyck M, et al. Variability of repairable bicuspid aortic valve phenotypes: towards an anatomical and repair-oriented classification. Eur J Cardiothorac Surg. February 20, 2019 [Epub ahead of print].

9. Boodhwani M, de Kerchove L, Glineur D, Rubay J, Vanoverschelde JL, Noirhomme P, et al. Repair of regurgitant bicuspid aortic valves: a systematic approach. J Thorac Cardiovasc Surg. 2010;140:276-84.

10. Schneider U, Feldner SK, Hofmann C, Schope J, Wagenpfeil S, Giebels C, et al. Two decades of experience with root remodeling and valve repair for bicuspid aortic valves. J Thorac Cardiovasc Surg. 2017;153:S65-71. 